\title{
Importance and Promotion of Gut Health in Broilers through Dietary Interventions
}

\author{
Muhammad Naeem*, Naeem Tahir and Zulfiqar Ali \\ University of Agriculture, Pakistan
}

*Corresponding author: Muhammad Naeem, Faisalabad, Pakistan

Submission: 侮 February 01, 2018; Published: 侮 March 01, 2018

\section{Introduction}

Animal protein is one of the major components meeting the food nutrient requirement for the everyday increasing population and poultry meat plays a vital role in meeting this animal protein requirement. Production of poultry (broilers) with high growth rate and feed efficiency are the two main targets. There are many factors which should be considered to get the optimum performance of the birds e.g. genetic potential of the birds, environmental conditions, disease out breaks and diets or feed. Feed counts for approximately 70 percent in the total cost of poultry production [1]. Apart from these, gut health has been the major focus of the intense studies in poultry production [2]. Gut is a vital organ of the digestive system which mediates nutrient uptake and use by the animals. The gut is also a major site of potential exposure to environmental pathogens [3]. Hence, a healthy gut is a foundation for optimum performance of the birds. If the gut health and its functions are impaired then digestion and absorption of the nutrients are affected and thus health and performance of the birds will be compromised [4]. Except for being responsible for absorption of the nutrients from lumen, intestinal mucosa of broiler chickens plays very important role in the provision of effective barrier between the hostile luminal content and the host internal tissues. So intestinal mucosa is important determinant of gut health and performance of chickens [2]. The dynamic balance between the mucus layer, epithelial cells, micro biota and immune cells in the intestine is of major importance for the intestinal mucosal barrier functions [5].

The use of antibiotics as growth promoters in poultry feed has been practiced worldwide during the last 5 decades [3]. and to maintain the balance of ecosystem in the gut and for the improvement in performance of chicken [6]. This application of antibiotics use has been well acknowledged for the improvement in the performance of birds including improvement in feed conversion and growth and reduction in morbidity and mortality due to clinical and sub clinical diseases. The mechanism by which antibiotics promote the growth of chickens are still not exactly known but study with germ-free chickens indicates that growth promoters are mediated by their antimicrobial effect [7]. Antibiotics may reduce the microbial load in the gut which leads to more availability of the nutrients for the host [8].
This practice of using the antibiotics has been questioned for the increase in prevalence of resistance to antibiotics in chicken [9]. Besides, the beneficial effects of antibiotics use as growth promoters, the transfer of antibiotic resistance genes from animal to human microbiota led the European Union to ban the use of antibiotics as growth promoters in January 2006. Today, there is concrete evidence the antibiotic resistance can pass into the food chain through bacteria like Salmonella spp. and Campylobacter spp., which are the most common causes of bacterial diarrhea in humans worldwide. Due to food safety concerns, four of the major US states have also signed up for in-feed antibiotics usage policy bans. The removal of antibiotics as growth promoters from poultry diets has led to problems in animal performance and rise in the incidence of certain poultry diseases e.g. (sub clinical) necrotic enteritis and Dysbacteriosis [6]. So, there is much need to find alternatives to antibiotics to maintain and promote the gut health for the improvement in the performance of birds.

Nutraceuticals are the additives which can be considered as alternatives of Antibiotics Growth Promoters (AGPs). These can be organic acids, exogenous enzymes, prebiotics, symbiotic, polyunsaturated fatty acids, phyto-biotics or changing the nutrients levels in diets or types of diets. Supplementing organic acids, exogenous enzymes and prebiotics is one of the dietary interventions which can lead to the improvement in the performance of the birds by promoting their gut health without the use of antibiotics.

\section{The Importance of microbiota balance}

Yegani \& Korver [3] reported several factors associated with diet and infectious disease agents that affect the biological or intestinal bacterial balance and consequently affect the health status and production performance of the birds. Kemmett [10] made the connection between the gut microbiota imbalance and poor growth performance. Choct [13] has found the negative effects of non-beneficial bacteria on gut morphology, nutrition, pathogenesis of intestinal diseases and immune response of the birds. After hatching the positive microbiota effect has a major effect on the overall health of a bird. There is direct contribution of undigested nutrients to undesirable shifts in the gut microbiota 
and these undigested nutrients flowing to the hind gut have shown an impact on performance of birds. This imbalance of microbiota affects the balance of mucus layer, epithelial cells and immune cells in the intestine and negatively affects feed conversion ratio and bird's health. Undigested protein, for example, has been shown as a factor linked to the establishment of Clostridium perfringens, coccidiosis and associated necrotic enteritis episodes in chickens [10]. Organic acids, exogenous enzymes and prebiotics are the major nutraceuticals used in the feed today to promote and help the gut health of the poultry birds now-a-days. It has been reported that all these nutraceuticals play a vital role in maintaining good health of the intestine and reducing the absorption of pathogenic bacteria of the intestine of the birds.

\section{Organic Acids}

Studies have shown that the use of organic acids have beneficial effects on the gut health and performance of broilers [12-14]. All these studies have shown that lactic acid bacteria count was increased in the intestine with the addition of organic acids. With this addition of organic acids, the count of Enterobacteriaceae and Salmonella has also been decreased $[12,15]$. Body weights and FCR was also improved with the addition of organic acids [13]. It has been reported that the antimicrobial activity of organic acids plays important role in controlling the population of pathogenic bacteria in the gut [16]. Van Immerseel et al. [17] reported that organic acids can easily diffuse through the semi-permeable membrane of the bacteria into the cell system when they are in the dissociated form. Organic acids with higher $\mathrm{pKa}$ ( $\mathrm{pH}$ at which acid is half dissociated) value are more effective antimicrobial compounds [6].

Dibner \& Buttin [18] reported that improved gut structure of chicken is associated with reduced number of pathogenic intestinal bacteria. It has also been reported that organic acids are associated with Histo-morphology of the gut by increasing the height of villus [13]. Organic acids are recognized having strong antibacterial properties which are very important to support the gut health of the birds and growth performance of poultry. The main mode of action of organic acids is to reduce the $\mathrm{pH}$ in the gastro-intestinal tract [4] which cause the alterations in the intestinal Ecosystem. It has been reported that organic acids should be provided in lower quantities because if they would be provided in excessive amount then they may cause reduction in the villus height and width and also the intestinal crypt length [19].

The main purpose of dietary supplementation of organic acids is to lower intestinal $\mathrm{pH}$ with the thinking of controlling microbial growth and colonization which result in lowering nutrients competition, the reduction of microbial metabolites and the decrease in incidence of sub-clinical infection [20], as well as organic acids stimulate the growth of intestinal absorptive cells, pancreatic secretion [21], and promote the whole growth performance of broiler chickens [22].

The main benefit of supplementing organic acids is to enhance growth performance of birds. This has been documented in many studies that addition of a single or combination of organic acids have improved growth performance of broiler chickens. Skinner et al. [23] reported that supplementation of fumaric acid in the diets significantly improved average daily gain and feed efficiency. A depression in growth of lactic acid and coliforms bacteria in the ileum and caeca was reported by Pirgozliev et al. [24]. One of many ways to control pathogenic bacteria population that are $\mathrm{pH}$ responsive is the reduction in $\mathrm{pH}$ of the intestinal gut of the birds. Dibner \& Buttin [18] reported in their study that dietary organic acid supplementation reduced population of E. coli, Salmonella and Campylobacter.

Paul et al. [25] reported that Ammonium Formate or Calcium Propionate supplementation promoted villus height. Another study of García et al. [22] showed that Formic Acid supplementation stimulated villus height and crypt depth of broiler chickens. The higher the villus and the greater the crypts showed high activity of proliferative cells due to organic acid inclusion, expecting to provide an adequate epithelium turnover rate. Increase in the number and size of crypts causes increase in intestinal absorptive surface area of the intestinal gut. Many studies showed that improvement of the intestinal Histomorphology in birds fed organic acids is believed to account for some of the growth-promoting properties of organic acids. On the other hand, the reduction of the organisms which produce toxins that can disrupt the villi and crypt structure, helps to account for the improvement in gut structure [18]. The Supplementation of organic acids must be in low doses because excessive dosage resulted in growth depression in intestinal villus height and width, as well as crypt depth [19]. Many of the organic acids are available now-a-days with different physical and chemical properties which are used in drinking water as well as in feed and they are present in single or combination forms [14].

\section{Exogenous Enzymes}

Combination of feed enzymes like xylanase, amylase and protease have been shown in reduction in the amount of undigested nutrients or substrate in the duodenum, jejunum and ileum increasing the digestibility of even so called simple diets and improving healthy broiler performance. Protease has effects in reducing undigested proteins and can also stimulate the production of mucus and could be associated with better responses of chickens in response to coccidial challenges. Enzyme like xylanase has been shown to produce Arabino-xylo-Oligosaccharides (AXOX) especially in the caecal phase. These act as prebiotics and selectively stimulate the growth of beneficial bacteria.

It has been reported that many enzymes like $\beta$-glucanase, xylanase, amylase, $\alpha$-galactosidase, lipase, phytase etc., have been in use since a long time [26,27]. Exogenous enzymes have been used mainly in the diet which are based on corn and soybean meal and they contain different level of anti-nutritive factors e.g. NSP and protease inhibitors and they are main hindrance in the process of normal digestion and absorption in the gut of the birds [28]. The tendency of reducing cost for the poultry feed by using non-conventional ingredients containing anti-nutritional factors and fibre, is also one of the causes to encourage the use of enzymes 
as these types of ingredients cannot be completely digested and absorbed by the chicken [29]. Exogenous enzymes are used to meet the lack of endogenous enzymes which are necessary for the digestion of certain type of nutrients in various feed stuff or hydrolysis for for anti-nutritional factors present in the feed stuffs. Costa et al. [29] reported the use of exogenous enzymes reduces the pollutant potential of excreta as it is an important environmental issue.

Gut health and enteric disease resistance is often dependent upon the digestibility of feed components and feed formulation. It has been reported that the gut health is compromised when poorly digested protein meals are given to birds. Langhout [30] reported that that dietary NSP significantly increases gut populations of pathogenic bacteria at the expense of beneficial bacteria. However, with the addition of exogenous enzymes including xylanases, phytases and $ß$-glucanases the digestibilities of wheat, rye and even corn-based diets can be improved. The response to dietary enzyme supplementation is greater when antibiotics are not used than when they are, but the performance responses do not approach the level that is observed when diets contain enzymes and antibiotics together [31]. Enzymes are perhaps the most extensively reviewed products those seem to limit the performance losses associated with removal of antibiotic growth promoters. The supplementation of enzymes enhances feed digestibilities and nutrients availability to the host through their beneficial effects, assuming they also influence the gut microbial ecosystem. The use of exogenous enzymes alters the gut microflora populations in the small intestine and caeca of the birds [31,32].

Adeola \& Coweison [26] reported that with the use of exogenous carbohydrase the proportion of lactic and organic acids and VFAs concentration was increased and ammonia production was decreased. The increased VFAs concentration helps the hydrolysis of NSP and supports the growth of beneficial bacteria in the gut of the broilers. Bedford \& Coweison [31] reported that exogenous enzymes modulate the gut microbiota of birds which may affect the health of the birds and the extent of digestion accomplished by the host. Generally speaking, the improvement in the nutrients digestibilities by the addition of exogenous enzymes is much smaller as compared to the loss of the substrate which must be available to the gut microflora, beneficial for the host [31].

\section{Prebiotics}

Prebiotics are non-digestible feeds stuffs or ingredients which affect the host beneficially by altering the composition and metabolism of the microbiota in the gut $[6,33]$. They may provide energy for the growth of endogenous bacteria which are favourable to the gut. Prebiotics have more benefits over the probiotics [34,35] and they play role in enhancing host defence and reducing the mortality caused by the invasion of gut pathogens [36]. Prebiotics directly target the colon, have selective fermentation and help in maintenance of a balanced microflora, preferably being utilized by promoting species and increased pathogens by faeces [37]. With the addition of prebiotics, the SCFAs production is more resulting in more acidity in the gut causing the suppression of pathogenic bacteria for the gut. Prebiotics also play an important role in the enhancement of immune response of the chickens [38].

Due to direct interaction between prebiotics and immune cells of gut, prebiotics enhance immune effect [39] and they have got similar mechanism as probiotics, support the gut health of the birds [6]. Non-digestible carbohydrate (Oligo and polysaccharides), some peptides and proteins, certain lipids are candidates for prebiotics amongst the food ingredients [37]. It has been reported that oligosaccharides are able to produce VFAs which stimulate peristalsis and decrease time to pass through intestine and may have a negative effect on digestibilities [37]. Trevino et al. [40] reported that there is increase in the length of jejunum, ileum and caecum in chicken such as length of villi in ileum. It has been reported that there is increase in daily weight gain approximately $8-10 \%$ with lower conversion at $10-15 \%$ with the use of prebiotics [37]. Dietary prebiotics supplementation is attributable to the improved birds' performance and energy utilization [11,41,42]. Kim et al. [38] reported that there was significant increase in the weight gain compared with control while differences in the feed intake, feed conversion and mortality were not observed [43-53].

The most common prebiotics used in the poultry are oligosaccharides, including inulin, Fructo-oligosaccharides (FOS), Mannan-oligosaccharides (MOS), galacto-Oligosaccharides (GOS), Soya-oligosaccharides (SOS), Xylo-oligosaccharides (XOS), pyrodextrin, Iso-malto-oligosaccharides (IMO) and lactulose [38]. Ganguly [36] reported that prebiotics cause increase in the production of SCFAs in the gastrointestinal tract which benefit the host as they recover some of the lost energy from competition with bacteria.

\section{References}

1. Naeem M (2003) Effect of floor space on the performance of broiler chicks. Msc (Hons) Thesis, University of Agriculture, Faisalabad, Pakistan.

2. Rinttila T, Apajalahti J (2013) Intestinal microbiota and metabolitesimplications for broiler chicken health and performance. The Journal of Applied Poultry Research 22(3): 647-658.

3. Yegani M, Korver DR (2008) Factors affecting intestinal health in poultry. Poult Sci 87(10): 2052-2063.

4. Sugiharto S (2016) Role of nutraceutical in gut health and growth performance of poultry. Journal of the Saudi Society of Agricultural Sciences (2016) 15:99-111.

5. Schenk M, Mueller C (2008) The mucosal immune system at the gastrointestinal barrier. Best Pract Res Clin Gastroenterol 22(3): 391409 .

6. Huyghebaert G, Ducatelle R Van Immerseel F (2011) An update on alternatives to antimicrobial growth promoters for broilers. Vet J 187(2): 182-188.

7. Yang Y, Iji PA, Choct M, (2009) Dietary modulation of gut microflora in broiler chickens: a review of the role of six kinds of alternatives to infeed antibiotics. World's Poultry Science Journal 65: 97-114.

8. Brisbin JT, Gong J, Sharif S (2008) Interactions between commensal bacteria and the gut-associated immune system of the chicken. Anim Health Res Rev 9(1): 101-110.

9. Kabir SML (2009) The role of probiotics in the poultry industry Int J Mol Sci 10(8): 3531-3546. 
10. Kemmett K (2015) Probiotics and enzymes: A good combination. World Poultry Magazine No. 2.

11. Choct M ( 2009) Managing gut health through nutrition. Br Poult Sci 50(1): 9-15.

12. SakiAA, HarciniRN, Rahmatnejad E, Salary J (2012) Herbal additives and organic acids as antibiotic alternatives in broiler chickens diet for organic production. Afr J Biotechnol 11: 2139-2145.

13. Adil S, Banday T, Bhat GA, Salahuddin, Raquib M, et al. (2011) Response of broiler chicken to dietary supplementation of organic acids. Journal of Central European Agriculture 12(3): 498-508.

14. Menconi A, Kuttappan VA, Hernandez-Velasco X, Urbano T, Matte F, et al. (2014) Evaluation of a commercially available organic acid product on body weight loss, carcass yield, and meat quality during preslaughter feed withdrawal in broiler chickens: a poultry welfare and economic perspective. Poult Sci 93(2): 448-455.

15. Cengiz O, Koksal BH, Tatli O, Sevim O, Avci H, et al. (2012) Influence of dietary organic acid blend supplementation and interaction with delayed feed access after hatch on broiler growth performance and intestinal health. Vet Med 57(10): 515-528.

16. PartanenK H, MrozZ (1999) Organic acids for performance enhancement in pig diets. Nutr Res Rev 12(1): 117-145.

17. Van Immerseel F, Russell JB, Flythe MD, Gantois I, Timbermont L (2006) The use of organic acids to combat Salmonella in poultry: a mechanistic explanation of the efficacy. Avian Pathol 35(3): 182-188.

18. Dibner JJ, ButtinP (2002) Use of organic acids as a model to study the impact of gut microflora on nutrition and metabolism. The Journal of Applied Poultry Research 11(4): 453-463.

19. Smulikowska S, Czerwinski J, Mieczkowska A (2010) Effect of an organic acid blend and phytase added to a rapeseed cakecontaining diet on performance, intestinal morphology, caecal microflora activity and thyroid status of broiler chickens. J Anim Physiol Anim Nutr (Berl) 94(1): $15-23$

20. Russell JB (1992) Another explanation for the toxicity of fermentation acids at low $\mathrm{pH}$ : Anion accumulation versus uncoupling. Journal of Applied Bacteriology 73: 363-370.

21. Dibner JJ ,RichardsJD( 2004) The digestive system: Challenges and opportunities. The Journal of Applied Poultry Research 13(1): 86-93.

22. García V, Catalá-Gregori P, Hernández F, Megías MD, Madrid J (2007) Effect of formic acid and plant extracts on growth, nutrient digestibility, intestine mucosa morphology, and meat yield of broilers. The Journal of Applied Poultry Research 16(4): 555- 562.

23. Skinner JT, Izat AL, Waldroup PW (1991) Research note - fumaric-acid enhances performance of broiler-chickens. Poult Sci. 70(6): 1444-1447.

24. Pirgozliev V, Murphy TC, Owens B, George J, Mccann MEE (2008) Fumaric and sorbic acid as additives in broiler feed. Res Vet Sci 84(3): 387-394.

25. Paul SK, Halder G, Mondal MK, Samanta G (2007) Effect of organic acid salt on the performance and gut health of broiler chicken. The Journal of Poultry Science 44(4): 389-395.

26. Adeola 0, Cowieson AJ (2011) Board-invited review: opportunities and challenges in using exogenous enzymes to improve nonruminant animal production. J Anim Sci 89(10): 3189-3218.

27. Bedford MR, Cowieson AJ (2012) Exogenous enzymes and their effects on intestinal microbiology. Anim Feed Sci Technol 173: 76-85.

28. Yegani M, Korver DR (2013) Effects of corn source and exogenous enzymes on growth performance and nutrient digestibility in broiler chickens. Poult Sci 92(5): 1208-1220.

29. Costa FGP, Goulart CC, Figueiredo DF, Oliveira CFS, Silva JHV (2008) Economic and environmental impact of using exogenous enzymes on poultry feeding. International Journal of Poultry Science 7(4): 311- 314.

30. Langhout DJ, JB Schutte, P van Leeuwen, J Wiebenga, S Tamminga (1999) Effect of dietary high- and low-methylated citrus pectin on the activity of the ileal microflora and morphology of the small intestinal wall of broiler chicks. Br Poult Sci 40(3) 340-347.

31. Bedford MR (2000) Exogenous enzymes in monogastric nutrition-Their current value and future benefits. Animal feed Science and Technology 86(s1_2): 1-13.

32. Choct M, R J Hughes, JWang, MR Bedford, AJ Morgan, et.al (1996) Increased small intestinal fermentation is partly responsible for the anti-nutritive activity of non-starch polysaccharides in chickens. $\mathrm{Br}$ Poult Sci 37(3): 609-621

33. Das L, Bhaumik E, Raychaudhuri U, ChakrabortyR (2012) Role of nutraceuticals in human health. J Food Sci Technol 49(2): 173-183.

34. Adil S, Magray SN, (2012) Impact and manipulation of gut microflora in poultry: a review. Journal of Animal and Veterinary Advances 11(6): 873-877.

35. Alloui MN, Szczurek W, Swiatkiewicz S (2013) The usefulness of prebiotics and probiotics in modern poultry nutrition review. Ann Anim Sci 13(1): 17-32.

36. Ganguly S (2013) Supplementation of prebiotics, probiotics and acids on immunity in poultry feed: a brief review. World Poult. Sci. J. 69: 639-648.

37. Sinovec Z, MarkovicR ( 2005) Using prebiotics in poultry nutrition. Biotechnology in Animal Husbandry 21(5-6): 235-239.

38. Kim GB, SeoYM, Kim CH, Paik IK (2011) Effect of dietary prebiotic supplementation on the performance, intestinal microflora, and immune response of broilers. Poult Sci 90(1): 75-82.

39. Janardhana V, Broadway MM, Bruce MP, Lowenthal JW, Geier MS, et.al (2009) Prebiotics modulate immune responses in gut-associated lymphoid tissue of chickens. The Journal of Nutrition 139(7): 14041409.

40. TrevinoJ, Centeno C Brenes, A Yuste, P Rubio L (1990) Effect of dieatary oligosaccharides on digestion of pea starch by growing chickes. Animal Feed Science Technology, 30, 313-319.

41. Yang Y, Ij I PA, KocherA, Mikkelsen LL, Choct M (2008) Effects of xylanase on growth and gut development of broiler chickens given a wheat-based diet. Asian-Aust. J Anim Sci 21(11): 1659-1664.

42. Nabizadeh A (2012) The effect of inulin on broiler chicken intestinal microflora, gut morphology, and performance. J Anim Feed Sci 21(4): 725-734.

43. Abdel Fattah SA, El-Sanhoury MH, El-Mednay NM, Abdel Azeem F (2008) Thyroid activity, some blood constituents, organs morphology and performance of broiler chicks fed supplemental organic acids. International Journal of Poultry Science 7(3): 215-222.

44. Ao T (2005) Exogenous enzymes and organic acids in the nutrition of broiler chicks: effect on growth performance and in vitro and in vivo digestion. University of Kentucky, USA.

45. Biggs P, Parsons CM (2007) The effects of several oligosaccharides on true amino acid digestibility and true metabolizable energy in cecectomized and conventional roosters. Poultry Science 86 (6): 11611165 .

46. Canibe N, Engberg RM, Jensen BB (2001) An overview of the effect of organic acids on gut flora and gut health. Proceeding of the Workshop: Alternatives to Feed Antibiotics and Coccidiostats in Pigs and Poultry (AFAC) Oslo, Norway, 13-16.

47. Chotikatum S, Kramomthong I, Angkanaporn K (2009) Effects of medium chain fatty acids, organic acids and fructo-oligosaccharide on cecal Salmonella enteritidis colonization and intestinal parameters of 
broilers. The Thai Journal of Veterinary Medicine 39(3).

48. Chowdhury R, Islam KMS, Khan MJ, Karim MR, Haque MN, et.al, (2009) Effect of citric acid, avilamycin, and their combination on the performance, tibia ash, and immune status of broilers. Poult Sci 88(8): 1616-1622.

49. Gauthier R (2002) Intestinal health, the key to productivity (the case of organic acids) XXVII Convencion ANECA-WPDSA Puerto Vallarta, Jal, Mexico.

50. Józefiak D, Kaczmarek S, Rutkowski A (2010) The effects of benzoic acid supplementation on the performance of broiler chickens. Journal of Animal Physiology and Animal Nutrition 94(1): 29-34.

51. Liem A, Pesti GM, Edwards Jr HM ( 2008) The effect of several organic acids on phytate phosphorus hydrolysis in broiler chicks. Poult Sci

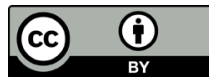

Creative Commons Attribution 4.0

International License

For possible submission use the below is the URL
87(4): 689-693.

52. Waldroup A, Kaniawati S, Mauromoustakos A (1995) Performance characteristics and microbiological aspects of broilers fed diets supplemented with organic acids. Journal of Food Protection ${ }^{8} 58(4)$ : 482-489.

53. Yang Y, Iji PA, Kocher A, Thomson E, Mikkelsen LL, et al. (2008) Effects of mannanoligosaccharide in broiler chicken diets on growth performance, energy utilisation, nutrient digestibility and intestinal microflora. $\mathrm{Br}$ Poult Sci 49(2): 186-194.

Your subsequent submission with Crimson Publishers will attain the below benefits

- High-level peer review and editorial services

- Freely accessible online immediately upon publication

- Authors retain the copyright to their work

- Licensing it under a Creative Commons license

- Visibility through different online platforms

- Global attainment for your research

- Article availability in different formats (Pdf, E-pub, Full Text)

- Endless customer service

- Reasonable Membership services

- Reprints availability upon request

- One step article tracking system 